statistically significantly different between all groups (Table). It also correlated statistically significantly with both the D12 score $(\mathrm{r}=0.586, \mathrm{~N}=23, \mathrm{p}=0.003)$ and Nijmegen score $(\mathrm{r}=0.418$, $\mathrm{N}=24, \mathrm{p}=0.042$ ) in the BPD group. There was no relationship between BPAT and $\mathrm{FEV}_{1} \%$ predicted or $6 \mathrm{MWT}$ distance.

Conclusion The BPAT score was higher in those patients diagnosed with BPD both with and without asthma. The BPAT score also correlates with both the D12 and Nijmegen score in patients diagnosed with BPD. This suggests it detects and characterises common aspects of BPD. Further work is now needed to validate the BPAT and determine its responsiveness to intervention.

\begin{tabular}{llll}
\multicolumn{2}{l}{ Abstract P228 Table 1 Median } & \multicolumn{3}{l}{ scores of outcomes per group } \\
\hline Group (M:F) & $\begin{array}{l}\text { Asthma } \mathrm{n}=14 \\
(6: 8)\end{array}$ & $\begin{array}{l}\text { Asthma+BPD } \mathrm{n}=37 \\
(9: 28)\end{array}$ & $\begin{array}{l}\text { BPD } \mathrm{n}=24 \\
(6: 18)\end{array}$ \\
\hline $\begin{array}{l}\text { Age median } \\
\text { (range) }\end{array}$ & $44.5(17-67)$ & $42.5(19-59)$ & $45(16-73)$ \\
BPAT & $3(0-8)^{*} \#$ & $7(2-12) \#$ & $6.5(3-13)^{*}$ \\
D12 & $19(6-29)$ & $23(5-37)$ & $18(4-32)$ \\
FEV $_{1 \%}$ & $59.4(114.5-32.6)$ & $76.5(127.2-39)$ & $99.8(60.7-132.4)$ \\
AQLQ $^{*}$ & $3.53(2.10-5.30)$ & $2.7(1.2-4.47)$ & $3.6(2.9-4.73)$ \\
\hline
\end{tabular}

$(p<0.05$ *Asthma v BPD, \#Asthma V Asthma+BPD, * BPD v Asthma+BPD)

\section{P229 BREATH-TAKING OUTCOMES: EVALUATION OF A SPECIALIST BREATHLESSNESS CLINIC}

${ }^{1} \mathrm{~L}$ Douglas, ${ }^{2} \mathrm{~A}$ English, ${ }^{2} \mathrm{GP}$ Obita, ${ }^{3} \mathrm{SP}$ Hart, ${ }^{3} \mathrm{MG}$ Crooks. ${ }^{1}$ Castle Hill Hospital, Hull and East Yorkshire Hospitals NHS Trust, Hull, UK; ${ }^{2}$ Dove House Hospice, Hull, UK; ${ }^{3}$ Hull York Medical School, Hull, UK

\subsection{6/thoraxjnl-2016-209333.372}

Background Breathlessness is distressing for patients and is a common reason for emergency department attendance. Chronic refractory breathlessness is associated with anxiety, embarrassment and fear, and effective management is essential to improve quality of life and reduce hospital admissions. ${ }^{1}$ Interventions such as breathing control, activity pacing and anxiety management are beneficial. ${ }^{2}$ This study examined the effect of attending a dedicated respiratory physiotherapist led breathlessness service on patient reported outcomes.

Method Patients attending the breathlessness clinic between April 2015 and April 2016 completed Numerical Rating Scales (NRS) out of 10 to grade their breathlessness. Data were collected before and 1-2 weeks after clinic attendance. Lower NRS scores represented a lower symptom burden. A change of 1 or more on the NRS was considered clinically significant. Responses were compared using t-tests and Wilcoxon signed-rank tests. Data are presented as mean $\pm \mathrm{SD}$.

Results Fifty-two patients attended the breathless clinic during the study period (mean age 73, range 49-92 years). Patients had a range of diagnoses causing their breathlessness with idiopathic pulmonary fibrosis (44.2\%), lung cancer (19.2\%), and non-specified interstitial lung disease (11.5\%) being most common.

Significant improvements were observed across all domains. Average breathlessness experienced in the past 24 hours reduced from $3.9 \pm 1.7$ to $3.6 \pm 1.6(\mathrm{p}=0.001)$. The worst breathlessness experienced in the past 24 hours reduced by 1 point to $6.3 \pm 1.9(\mathrm{p}<0.001)$. The distress experienced from breathlessness reduced from $5.8 \pm 6.4$ to $4.8 \pm 4.8$ (p < 0.001). Patients' perceived ability to cope with their breathlessness improved by 1 point $(\mathrm{p}<0.001)$.
Conclusions A specialist breathlessness clinic provided a valuable service for patients with chronic refractory breathlessness. Significant, clinically meaningful benefits were observed in terms of the severity of breathlessness that patients experienced. Furthermore, patients perceived a reduction in distress and increased ability to cope.

\section{REFERENCES}

1 Ekström M, Abernethy A, Currow D. The management of chronic breathlessness in patients with advanced and terminal illness. BMJ 2015;349:g7617.

2 Higginson IJ, Bausewein C, Reilly C, et al. An integrated palliative and respiratory care service for patients with advanced disease and refractory breathlessness: a randomised controlled trial. Lancet Respiratory Medicine 2014;2:979-87.

\section{P230 EVALUATION OF A NOVEL DYSFUNCTIONAL BREATHING SERVICE}

${ }^{1} \mathrm{CP}$ Winfield, ${ }^{2} \mathrm{C}$ Moffat, ${ }^{2} \mathrm{R}$ Hurst, ${ }^{2} \mathrm{JP}$ Fuld. ' University of Cambridge School of Clinical Medicine, Cambridge, UK; ${ }^{2}$ Cambridge University Hospitals, Cambridge, UK

\subsection{6/thoraxjnl-2016-209333.373}

Introduction and objectives Despite multiple trials, there remains a lack of consensus on the optimum management of dysfunctional breathing patients. ${ }^{1}$ This service evaluation considers the effectiveness of a novel, multi-factorial intervention, consisting of cardiopulmonary exercise testing (CPET), explanation of physiological findings and breathing retraining, for those suffering from dysfunctional breathing.

Methods Patients who had a history of likely dysfunctional breathing combined with CPET evidence of dysfunctional breathing, hyperventilation or lack of underlying pathology were invited to attend a joint consultation with a respiratory physician and a physiotherapist. To date, fourteen patients have attended initial consultation and six patients have completed full follow up. All patients received chest consultant clinical consultation where their CPET findings were reviewed with them, with particular emphasis on fitness, evidence of underlying disease and breathing pattern. Initial physiotherapist consultation was followed by a bespoke breathing retraining programme. The Nijmegan questionnaire and the self-evaluation of breathing questionnaire formed the main outcome measures. Patients also completed a service satisfaction questionnaire, rating 6 aspects of the service on a scale of $1-5$, with 5 being most satisfied. Paired $\mathrm{t}$-tests were used to calculate significance of pre and post values.

Results Fourteen patients have so far been assessed in the initial consultation. Their diagnosis and breathing patterns, demonstrated on CPET, are described in Table 1. Average pre-trial Nijmegan Questionnaire scores demonstrated an improvement postintervention from the 6 patients who have completed the intervention (26.5 pre to 21.2 post, $\mathrm{p}=0.0465)$. Patients also completed the self-evaluation of breathing questionnaire, before and after the intervention. The average score decreased from 27.2 pre-trial to 15.0 post-trial ( $\mathrm{p}=0.0098$ ). No changes in functional residual capacity controlled pause $(10.0 \mathrm{~s}$ pre to $11.8 \mathrm{~s}$ post, $\mathrm{p}>0.05)$ or total lung capacity breath hold (11.8s pre to $21.0 \mathrm{~s}$ post, $\mathrm{p}>0.05)$ were evident. The average patient satisfaction score was 28.6/30.

Conclusion A novel combined physiological and physiotherapist based intervention may be effective in supporting symptoms in people with dysfunctional breathing. 